\title{
Cusp repair in aortic valve reconstruction: Does the technique affect stability?
}

Diana Aicher, MD, Frank Langer, MD, Oliver Adam, MD, Dietmar Tscholl, MD, Henning Lausberg, MD, and Hans-Joachim Schäfers, MD

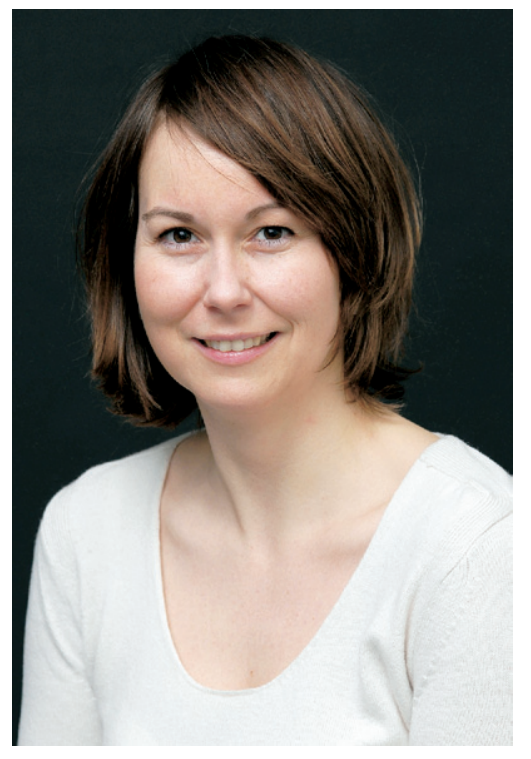

Dr Diana Aicher
From the Department of Thoracic and Cardiovascular Surgery, University of Saarland Homburg/ Saar, Germany.

Read at the Eighty-seventh Annual Meeting of The American Association for Thoracic Surgery, Washington, DC, May 5-9, 2007.

Received for publication April 6, 2007; revisions received Aug 9, 2007; accepted for publication Aug 27, 2007.

Address for reprints: H.-J. Schäfers, MD, Department of Thoracic and Cardiovascular Surgery, University Hospital of Saarland, 66421 Homburg/Saar, Germany (E-mail: h-j.schaefers@uniklinikum-saarland.de)

J Thorac Cardiovasc Surg 2007;134:1533-9

$0022-5223 / \$ 32.00$

Copyright $($ C 2007 by The American Association for Thoracic Surgery

doi:10.1016/j.jtcvs.2007.08.023
Objective: Cusp prolapse may be an isolated cause of aortic regurgitation or may exist in conjunction with dilatation of the proximal aorta. Prolapse can be corrected by central plication, triangular resection, or pericardial patch implantation. We retrospectively analyzed our results with these techniques.

Methods: From October 1995 to December 2006, 604 patients (aged 3-86 years) underwent aortic valve repair. Cusp prolapse was found in 427 patients (246 tricuspid, 181 bicuspid). Prolapse was corrected by central plication $(n=275)$ or triangular resection $(\mathrm{n}=80)$. A pericardial patch was implanted for pre-existing cusp defects or after excision of calcium $(\mathrm{n}=72)$. One cusp was repaired in 198 patients; the remaining patients underwent repair of $2(n=189)$ or 3 cusps $(n=40)$. In 102 patients more than one technique was used, and the patients were allocated to the group of the assumedly more complex repair (central plication $<$ triangular resection $<$ pericardial patch plasty). Cumulative follow-up was 1238 patient-years (mean $35 \pm 27$ months).

Results: Hospital mortality was $2.6 \%$ (11/427). Actuarial freedom from aortic regurgitation of grade II or more at 5 years was $92 \%$ (central plication), $90 \%$ (triangular resection), and 90\% (pericardial patch plasty). Thirteen patients were reoperated on, with prolapse as the most common reason for failure $(\mathrm{n}=7) ; 6$ underwent re-repair. Freedom from reoperation at 5 years was 95\% (central plication), 94\% (triangular resection), and 94\% (pericardial patch plasty). Freedom from valve replacement at 5 years was $97 \%$ (central plication), 99\% (triangular resection), and $98 \%$ (pericardial patch plasty).

Conclusions: In aortic valve repair, cusp prolapse can be treated reliably by central plication. In the presence of more complex disease, triangular resection or pericardial patch plasty may be used without compromising midterm durability.

$\mathrm{T}$ The success with valve-sparing aortic replacement has revived the interest in aortic valve (AV) repair. The traditional application of valve-sparing surgery has been in patients with normal aortic cusps. Cusp prolapse, however, may be present in conjunction with aortic dilatation ${ }^{1-3}$ and cusps may actually be deformed owing to chronic aortic dilatation. ${ }^{4}$

Cusp prolapse is also a frequent cause of aortic regurgitation (AR) without dilatation of the aortic root, ${ }^{5}$ in both bicuspid and tricuspid AV anatomy. In these patients, correction of cusp geometry is the primary goal of AV repair. Plication of the free cusp margin has been performed in the paracommissural zone. ${ }^{6-8}$ We have preferred central plication $(\mathrm{CP})$ of the free cusp margin for correction of prolapse in both bicuspid and tricuspid anatomy. We have consistently applied this technique in the presence of normal root dimensions and in conjunction with valve-preserving aortic replacement. ${ }^{3,9}$ 


\section{Abbreviations and Acronyms \\ $\mathrm{AR}=$ aortic regurgitation \\ $\mathrm{AV}=$ aortic valve \\ $\mathrm{CP}=$ central plication \\ $\mathrm{PP}=$ pericardial patch \\ $\mathrm{TR}=$ triangular resection}

Triangular resection (TR) of cusp tissue was described by Carpentier ${ }^{10}$ and systematically used by others for repair of regurgitant bicuspid and tricuspid AVs. ${ }^{6,7,}{ }^{11}$ A later analysis, however, identified TR as a risk factor for secondary failure and reoperation. ${ }^{12}$

Pericardial patch (PP) insertion for AV repair was first used by Ross ${ }^{13}$ in 1963 and has been used for cusp replacement or extension in rheumatic and congenital AV disease. ${ }^{14-17}$ Few long-term results have been published, but glutaraldehyde-treated pericardium appears to be a stable substitute for aortic cusps. ${ }^{18}$ Pericardium can also be used to stabilize aortic cusps that prolapse in the presence of congenital fenestrations, and it may also be used for correction of defects after excision of a calcified raphe in prolapsing bicuspid valves.

Of these techniques, $\mathrm{CP}$ of the cusp margin appears to be the least complex technique, and it allows for stepwise adjustment of cusp geometry. TR involves a higher level of surgical judgment regarding extent of resection, and it carries the risk of suture line dehiscence. Partial replacement of cusp tissue includes, by definition, a longer suture line, and there are possible concerns regarding midterm stability and freedom from calcification of the implanted pericardium.

Currently there are no data from any single surgical group comparing these techniques of cusp repair. We therefore analyzed our results with these techniques.

\section{Patients and Methods \\ Patients}

From October 1995 to December 2006, 604 patients (aged 3-86) underwent AV repair. Patients who did not require cusp repair in conjunction with valve-preserving surgery and patients with primary cusp retraction, active endocarditis, or predominant stenosis were excluded. Cusp prolapse requiring correction was found in 427 patients, and these patients are the subject of the current investigation. Data were collected prospectively and analyzed in a retrospective fashion.

In 140 of these patients root dimensions were normal, and in 287 individuals dilatation of the aorta was present. Aortic dilatation was corrected by supracommissural aortic replacement $(\mathrm{n}=$ 91) or root replacement $(\mathrm{n}=196)$ by either root remodeling $(\mathrm{n}=$ 186) or AV reimplantation $(\mathrm{n}=10)$.

Preoperative AR was grade II in $25 \%$, grade III in $59 \%$, and grade IV in $16 \%$. The primary indication for the operation was acute dissection in 28 patients, ascending aortic aneurysm in 119 patients, AR in 266 patients, mitral regurgitation in 10, and coronary artery disease in 4 patients.

\section{Surgical Technique}

The ascending aorta was opened by a transverse aortotomy or completely transsected 5 to $10 \mathrm{~mm}$ above the commissures. The aortic root was placed under radial tension by stay sutures placed in each commissure. The cusps were carefully inspected for congenital fenestrations or postendocarditic defects or the presence of fibrosis or calcification. The relative lengths of the different free cusp margins were compared with each other. In the most recent 2 years, we additionally measured the height difference between the central free margin and the lowest point of the aortic insertion of each cusp (ie, effective height). ${ }^{19}$

Prolapse was initially defined as a difference in the central height of a free margin relative to the other margin(s) of $2 \mathrm{~mm}$ or more. In the past 2 years, an effective height of less than $7 \mathrm{~mm}$ has been considered as an indicator of prolapse. Prolapse was common in the congenitally fused cusp of bicuspid AVs $(n=61)$. Another frequent finding of prolapse was prolapse in conjunction with correction of aortic dilatation (bicuspid AVs, $\mathrm{n}=120$; tricuspid AVs, $\mathrm{n}=167)$. Prolapse associated with cusp fenestrations was seen in tricuspid $(\mathrm{n}=28)$ and in bicuspid AVs $(\mathrm{n}=8)$. Concomitant cusp fibrosis or calcification was found in 116 valves (bicuspid, $\mathrm{n}=101$; tricuspid, $\mathrm{n}=15$ ).

For correction of prolapse, plication of the central portion of the free margin $(\mathrm{CP})$ was performed as the preferred technique with single 5-0 or 6-0 Prolene sutures (Ethicon, Inc, Hamburg, Germany). Depending on the extent of prolapse, 1 to 5 plication stitches were placed in a stepwise fashion until an adequate cusp configuration was achieved.

In the presence of marked tissue redundancy $(>10 \mathrm{~mm})$ or dense fibrosis/calcification in the raphe of a bicuspid AV, a TR was chosen. A limited central resection of cusp tissue was performed, and the remaining tissue was readapted by interrupted stitches (6-0 Prolene sutures).

If the resulting tissue defect after TR was too large to allow for direct readaption, a PP patch was inserted. Autologous pericardium for cusp reconstruction was also used in the presence of congenital fenestrations $(n=36)$. A piece of pericardium was fixed on a piece of cardbord with hemoclips, pretreated for 2 to 3 minutes in $1 \%$ glutaraldehyde solution, and rinsed in saline for 5 minutes. A patch of adequate size was cut and sutured into the defect with a running suture.

Independent of the type of cusp repair used, we aimed to achieve an identical height of the free margins, and in the past 2 years an effective height of 7 to $8 \mathrm{~mm}$ in tricuspid and 8 to $10 \mathrm{~mm}$ in bicuspid AVs.

Twenty-eight patients were operated on under emergency conditions for type A dissection. Sixteen patients had previous cardiac surgery, and 10 patients had Marfan syndrome. Eighty-seven patients had concomitant coronary artery disease, and 39 had mitral regurgitation. Of 287 patients with aortic dilatation, 106 had concomitant dilatation of the aortic arch. Additional procedures were coronary artery bypass surgery $(\mathrm{n}=87)$, mitral valve repair $(\mathrm{n}=$ $39)$, and partial $(\mathrm{n}=87)$ or total $(\mathrm{n}=19)$ arch replacement.

All patients were studied intraoperatively by transesophageal echocardiography. The degree of AR was determined primarily by 
TABLE 1. Demographic data of patients with cusp prolapse

\begin{tabular}{|c|c|c|c|c|}
\hline & $\mathrm{CP}(\mathrm{n}=275)$ & $\operatorname{TR}(\mathrm{n}=\mathbf{8 0})$ & $\mathrm{PP}(\mathrm{n}=72)$ & $P$ value \\
\hline Age (y) & $58 \pm 17$ & $49 \pm 16$ & $52 \pm 18$ & $<.001$ \\
\hline Gender (M/F) & $189 / 86$ & $69 / 11$ & $62 / 10$ & $<.001$ \\
\hline Bicuspid AV (n) & $70(26 \%)$ & $74(93 \%)$ & $37(51 \%)$ & $<.0001$ \\
\hline $\operatorname{AADA}(\mathrm{n})$ & 27 & 0 & 1 & .0012 \\
\hline AR (grade) & $2.8 \pm 0.7$ & $2.8 \pm 0.6$ & $3.0 \pm 0.7$ & .58 \\
\hline Previous cardiac surgery (n) & 13 & 0 & 3 & .14 \\
\hline Marfan (n) & 10 & 0 & 0 & .06 \\
\hline CABG (n) & 68 & 6 & 13 & .003 \\
\hline Mitral valve repair (n) & 33 & 3 & 3 & .02 \\
\hline \multicolumn{5}{|l|}{ Arch replacement (n) } \\
\hline Partial & 76 & 5 & 6 & $<.0001$ \\
\hline Total & 18 & 0 & 1 & .02 \\
\hline CPB time (min) & $101 \pm 40$ & $81 \pm 27$ & $81 \pm 26$ & $<.0001$ \\
\hline CPB (min) for isolated AV repair & $51 \pm 16$ & $53 \pm 16$ & $61 \pm 14$ & .017 \\
\hline Aortic crossclamp time (min) & $69 \pm 26$ & $58 \pm 23$ & $61 \pm 21$ & .0006 \\
\hline Aortic crossclamp time (min) for isolated AV repair & $32 \pm 13$ & $34 \pm 10$ & $44 \pm 11$ & $<.0001$ \\
\hline
\end{tabular}

$C P$, Central plication; $T R$, triangular resection; $P P$, pericardial patch; $A V$, aortic valve; $A A D A$, acute type $\mathrm{A}$ aortic dissection; $A R$, aortic regurgitation; $C A B G$, coronary artery bypass grafting; $C P B$, cardiopulmonary bypass.

the size of the regurgitant jet assessed by color Doppler and the downward slope of the continuous-wave Doppler. ${ }^{20}$ All patients were studied at least once before discharge, that is, between postoperative days 5 and 7. Further transthoracic echocardiograms were performed at 6 and 12 months and yearly thereafter. Follow-up was complete in $97 \%$ of patients and ranged from 1 to 133 months (mean $35 \pm 27$ months) for a cumulative follow-up of 1238 patient-years.

\section{Study Groups}

The patients were divided into three groups according to the used repair technique (i.e. CP, TR, and PP). If different techniques were used in one valve at different cusps, the more complex repair procedure determined the group allocation according to the complexity of the repair $(\mathrm{CP}<\mathrm{TR}<\mathrm{PP})$.

\section{Statistical Analysis}

All data are presented as mean \pm standard deviation. Statistical analysis included comparison of parametric and continuous variables between the groups by 1-way analysis of variance. Kaplan-Meier curves were calculated for freedom of relevant regurgitation, freedom from reoperation, and freedom from valve replacement with a commercially available software package (Prism; GraphPad Inc, San Diego, Calif). The curves were compared between the groups by the Mantel-Haenszel log-rank test.

\section{Results}

In 246 tricuspid AVs, prolapse was corrected on one $(\mathrm{n}=$ 129), two ( $\mathrm{n}=77)$, and three $(\mathrm{n}=40)$ cusps. In 181 bicuspid AVs, prolapse was corrected on one $(n=69)$ and two $(\mathrm{n}=112)$ cusps. In 102 cases more than one technique was used. Of all patients, 275 were allocated to $\mathrm{CP}, 80$ to TR, and 72 to PP.
The groups were not directly comparable with respect to several of the clinical data analyzed (Table 1). Patients were older in the CP group (58 \pm 17 years) compared with the TR $(49 \pm 16$ years $)$ or PP groups $(52 \pm 18$ years; $P<.001)$. Concomitant procedures were more frequent in $\mathrm{CP}$ (aortic root replacement, $P<.001$; coronary artery bypass grafting, $P<.01)$. Most important, the techniques required for valve reconstruction included significantly less frequent use of TR and more CP for cusp repair in tricuspid AVs. Cardiopulmonary bypass time and ischemia were longer for PP insertion than for CP or TR $(P=.017 ; P<.0001)$.

Hospital mortality for all patients was $2.6 \%$ (11/427). Mortality for isolated AV repair without any other surgical procedure was $1.2 \%(1 / 86)$. Nine patients died after AV repair with CP $(9 / 275,3.3 \%)$. Two of these patients had undergone surgery for acute dissection; 6 patients had concomitant coronary artery disease, 2 of them with previous coronary bypass surgery. Two patients died after AV repair with $\operatorname{TR}(2 / 80,2.5 \%)$. The causes of death were sepsis $(\mathrm{n}=$ $2)$ or mesenteric ischemia $(n=4)$ with multiple organ failure, ventricular arrhythmia $(n=1)$, liver failure $(n=1)$, and left ventricular failure $(n=3)$. The latter 3 had concomitant coronary artery bypass surgery, 1 as a redo operation.

No patient died after PP plasty, and no death was related to dysfunction of the reconstructed AV.

Survival at 5 years was $91 \%$ after CP, $99 \%$ after TR, and $89 \%$ after PP $(P=.06)$. There were 2 episodes of thromboembolism (CP 1, PP 1) within 6 weeks postoperatively in conjunction with intermittent atrial fibrillation. Endocarditis developed early postoperatively in 2 patients (CP 1, PP 1), 


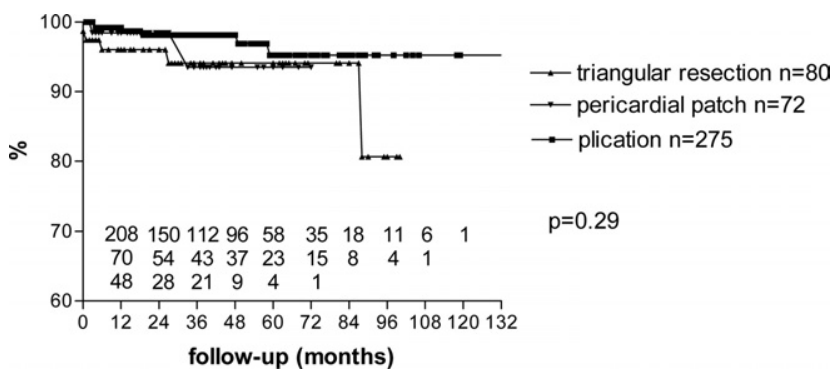

Figure 1. Freedom from reoperation after the three different cusp repair techniques.

resulting in a linearized incidence of endocarditis of $0.16 \% /$ patient-year.

Thirteen patients required reoperation (CP 6, TR 5, PP 2) for suture dehiscence $(\mathrm{n}=2)$, secondary root dilatation (n $=1)$, and cusp retraction $(\mathrm{n}=1)$. The 2 individuals who had endocarditis were reoperated on within the first postoperative year after healing of endocarditis. In all other patients $(n=7)$ prolapse was the reason for reoperation. In 6 patients the valve was re-repaired, including the 2 with suture dehiscence. Freedom from reoperation at 5 years was 95\% (CP), 94\% (TR), and 94\% (PP; $P=.3$; Figure 1). Freedom from valve replacement at 5 years was $97 \%(\mathrm{CP})$, 99\% (TR), and 98\% (PP; $P=.9$ ).

Residual AR grade II was found in 11 patients at discharge, in an additional 11 within the first year, and in 4 during subsequent follow-up. Actuarial freedom from AR grade II or more at 5 years was $92 \%$ (CP), 90\% (TR), and $90 \%$ (PP; $P=.99$; Figure 2). Of the 11 patients who had AR grade II at discharge, 7 had to be reoperated on within the first year and an additional 4 within the first 5 years. Of the additional 11 individuals who left the hospital with AR less than grade II but had grade II at 1 year, only 1 had to be reoperated on within the first 5 years. The other patients have remained in stable condition. Development of AR grade II early postoperatively is a risk factor for reoperation.

Within the PP group there was no difference regarding valve stability if the patch was used for closing fenestrations or partial replacement of cusps $(P=.40)$. There was no difference in valve stability after the different repair procedures for repair of bicuspid or tricuspid AVs $(\mathrm{CP}, P=.7$; $\mathrm{TR}, P=.5$; PP, $P=.6$ ). Overall freedom from AR grade II or more at 5 years was $90 \%$ in both anatomic variants (Figure 3). We found an influence of preoperative degree of AR on valve stability. Freedom from AR of grade II or more after 3 and 5 years was $97 \%$ and $92 \%$ for preoperative AR grade II, 93\% for preoperative AR grade III, and $86 \%$ and $75 \%$ for preoperative AR grade IV $(P=.02)$. Freedom from reoperation after 3 and 5 years was $99 \%$ for preoperative AR grade II, 96\% and 93\% for preoperative AR grade III, and $91 \%$ for preoperative AR grade IV $(P=.09)$.

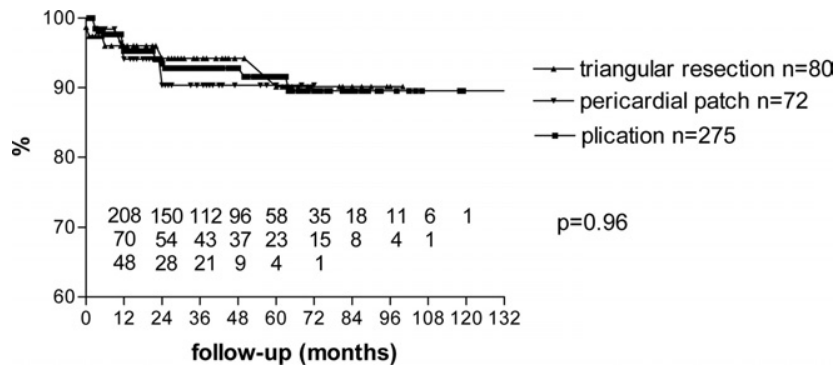

Figure 2. Freedom from aortic regurgitation of grade II or more after the three different cusp repair techniques.

\section{Discussion}

Cusp prolapse of the AV is a common cause of AR in bicuspid and tricuspid AVs. The true incidence is difficult to judge because currently there is no clear definition of prolapse and consequently information regarding its frequency and causes is limited. ${ }^{5}$ Cusp prolapse can occasionally be visualized by 2 -dimensional echocardiography, but its recognition by color flow Doppler jet is probably more reliable. Pure annular dilation or cusp restriction is associated with central jet direction and origin, whereas any eccentric regurgitant jet suggests cusp prolapse. ${ }^{21,22}$

Cusp geometry is also difficult to judge intraoperatively. Cusp dimensions in relation to sinus dimensions determine the configuration of the AV, and the exact dimensions are difficult to measure. ${ }^{4}$ To find an easier parameter, we introduced measurement of the effective height, as the height difference between the central free margin and the aortic insertion lines. ${ }^{19}$ A caliper allows easy and reproducible measurement of the effective height of the cusps. We have found this approach particularly helpful in patients with prolapse of more than one cusp.

In case of limited cusp prolapse, we used plication stitches in the central portion of the free edge of the cusp (CP technique). The concept of paracommissural plication has been used particularly in AR associated with ventricular

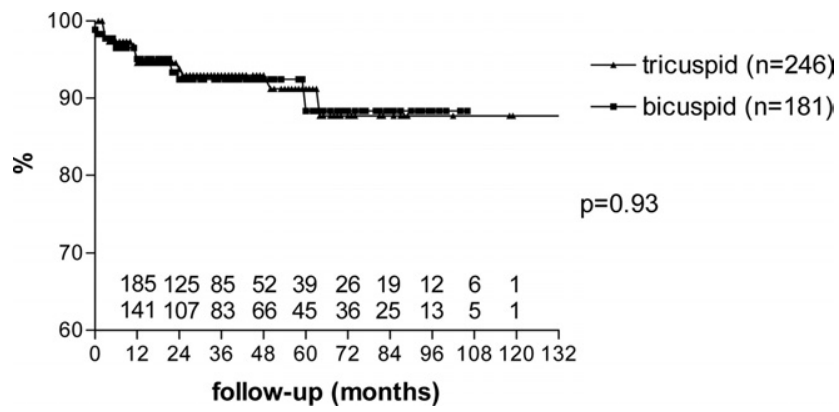

Figure 3. Freedom from aortic regurgitation of grade II or more in bicuspid and tricuspid aortic valves (all repair techniques combined). 
septal defects. ${ }^{23,24}$ Trusler and associates ${ }^{25}$ reported a series of 70 patients with a 10-year freedom from valvuloplasty failure and freedom from reoperation of $76 \%$ and $85 \%$, respectively. In contrast, we always use $\mathrm{CP}$ sutures, which were possibly first used in 1961 by Spencer, Bahnson, and Neill. ${ }^{26}$ The differential stress distribution at the cusp free edge shows maximal stress near the commissure and minimal stress near the central portion of the free edge and therefore favors $\mathrm{CP} .{ }^{27}$ Compared with the paracommissural approach, our results for $\mathrm{CP}$ show better valve stability with 90\% freedom from AR grade II or more and $95 \%$ freedom from reoperation at 10 years. In addition, the stepwise placement of plicating sutures appears reasonable, because overcorrection can be reversed easily by removal of the last suture. We have not encountered late sequelae of these sutures, such as calcification in plicated areas of the free margin or torn out sutures after CP.

In the presence of a more extensive prolapse, we have performed a triangular resection (TR) to avoid excessive bulging of plicated cusp tissue. Its advantage over simple plication in this setting is unclear. TR is definitely necessary in case of dense fibrosis or calcification, where plication cannot be performed. This is rare in tricuspid AVs, but common in bicuspid AVs with a fibrosed or calcified median raphe. Haydar and colleagues, ${ }^{6}$ who performed TR in 11 patients, found recurrent AR in 3 patients with the need for reoperation (27\%). No details about valve anatomy and reasons for failure are given in this publication. ${ }^{6}$ TR of cusp tissue appeared as a risk factor for repair failure in bicuspid $\mathrm{AVs}$ in an analysis from the Cleveland Clinic, with $14 \%$ $(9 / 66)$ of patients requiring reoperation. ${ }^{12}$ We observed a low failure rate of $6 \%(5 / 80)$ after TR. A reason for this difference may be that we frequently corrected prolapse of both cusps in bicuspid AVs $(112 / 181=62 \%)$, whereas Casselman and colleagues ${ }^{12}$ apparently corrected only one cusp and therefore may have underestimated existing cusp pathology.

We used pericardial patch (PP) insertion for closure of congenital fenestrations that had led to cusp prolapse to provide better stress distribution in the paracommisural zone. Others have used a polytetrafluoroethylene suture (Gore-Tex suture; W. L. Gore \& Associates, Inc, Flagstaff, Ariz) placed in the free margin for stabilization. ${ }^{28}$ Currently, no data on durability of the latter approach are available. Inasmuch as almost all of our valves repaired in such a way have remained stable, our current approach appears to be a good and reproducible option.

Another indication for PP insertion has been partial cusp replacement after TR if the resulting tissue defect was too large for direct readaption. Cusp replacement by pericardium has been performed before for several indications. Alsoufi and associates ${ }^{17}$ used cusp extension with pericardium for congenital AV disease and reported a 5-year freedom from valve replacement of $75 \%$. Pretre and colleagues ${ }^{29}$ used pericardium for tricuspidalization of regurgitant bicuspid AVs with a follow-up of less than 4 years. Tolan and associates ${ }^{30}$ also used pericardium for tricuspidalization in stenotic bicuspid AVs, but again the follow-up was short with a maximum of 60 months. Al-Halees and associates ${ }^{18}$ used a single strip of pericardium for extension or replacement of all three aortic cusps in mixed AV disease and reported a good durability of autologous pericardium with freedom from structural valve degeneration of $80 \%$ at 10 years. With our limited follow-up-72 months of longest follow-up and a mean of $22 \pm 18$ months-our results are similarly good with a freedom from reoperation at 5 years of 94\%. Further follow-up will determine the role of pericardium in $\mathrm{AV}$ reconstruction.

Despite the overall encouraging good results of cusp repair, we encountered 13 failures requiring reoperation. In most patients $(\mathrm{n}=7)$ a residual prolapse was already seen early postoperatively in conjunction with improved but persisting AR. Its degree increased over time and ultimately led to reoperation. In retrospect, these valves were undercorrected and failure may have been prevented by more aggressive surgery at the time of initial cusp repair. The initial reoperations were performed as valve replacement $(n=3)$. More recently, and with better recognition of prolapse, we have been able to re-repair these valves $(n=4)$. Actual repair failure, for example, suture breakdown, was rare $(\mathrm{n}=$ 2: 2 hours postoperatively and 9 days). In both instances, TR with direct suture had been performed initially. Possibly, restricted cusp motion and excessive tension contributed to suture dehiscence in both instances. In both patients the valve could be re-repaired by implantation of a pericardial patch, and both continue to have stable function in the follow-up. Partial cusp replacement thus may reduce tension on the suture line.

The major limitation of the current investigation is the fact that the three techniques for cusp repair are not directly comparable, and they were used for different pathologic conditions. In a calcified cusp, for example, simple CP is not possible, whereas in the presence of pliable cusp tissue, nobody would consider PP insertion. With pliable cusp tissue and a larger prolapse, one can consider either $\mathrm{CP}$ or $\mathrm{TR}$, but it appears advisable to decide for the least complex technique. Consequently, the three patient groups are not similar and comparable. On the other hand, it was not our goal to compare patient-related variables, but simply relative durability of the repair techniques. In addition, our definition of prolapse changed over time. To improve reproducibility and decrease the influence of subjective surgical judgment, we introduced the measurement of the effective height. ${ }^{19}$ Most important, the intraoperative determination of this surrogate of cusp configuration has allowed us to avoid the generation of symmetric prolapse, 
which was a reason for reoperation in 7 patients. We have found this particularly helpful in the last 140 repairs.

Finally, this is a retrospective and nonrandomized analysis. From a scientific standpoint, a prospective randomized trial comparing different cusp repair procedures would be preferable. Longer follow-up will be necessary to confirm the present results.

Correction of cusp prolapse is possible by different techniques, such as plication of the free margin and TR of redundant cusp tissue. All techniques have worked similarly well in our hands with comparable midterm results. Even more complex cusp repair is possible with autologous pericardial tissue, allowing for correction of congenital or acquired defects or resection of limited calcifications. This has been feasible without compromising midterm valve stability. All techniques can be used, provided that adequate cusp configuration can be achieved. Longer follow up will be necessary to judge the long-term results of the different techniques.

\section{References}

1. Agozzino L, de Vivo F, Falco A, Luca Tupputi SL, Cotrufo M. Non-inflammatory aortic root disease and floppy aortic valve as cause of isolated regurgitation: a clinico-morphologic study. Int J Cardiol. 1994;45:129-34.

2. Bellitti R, Caruso A, Festa M, Mazzei V, Iesu S, Falco A, et al. Prolapse of the "floppy" aortic valve as a cause of aortic regurgitation. A clinico-morphologic study. Int J Cardiol. 1985;9:399-412.

3. Langer F, Graeter T, Nikoloudakis N, Aicher D, Wendler O, Schafers HJ. Valve-preserving aortic replacement: does the additional repair of leaflet prolapse adversely affect the results? J Thorac Cardiovasc Surg. 2001;122:270-7.

4. Thubrikar MJ, Labrosse MR, Zehr KJ, Robicsek F, Gong GG, Fowler BL. Aortic root dilatation may alter the dimensions of the valve leaflets. Eur J Cardiothorac Surg. 2005;28:850-5.

5. Shapiro LM, Thwaites B, Westgate C, Donaldson R. Prevalence and clinical significance of aortic valve prolapse. Br Heart J. 1985;54:17983.

6. Haydar HS, He GW, Hovaguimian H, McIrvin DM, King DH, Starr A. Valve repair for aortic insufficiency: surgical classification and techniques. Eur J Cardiothorac Surg. 1997;11:258-65.

7. Cosgrove DM, Rosenkranz ER, Hendren WG, Bartlett JC, Stewart WJ. Valvuloplasty for aortic insufficiency. J Thorac Cardiovasc Surg. 1991;102:571-6.

8. Trusler GA, Moes CA, Kidd BS. Repair of ventricular septal defect with aortic insufficiency. J Thorac Cardiovasc Surg. 1973;66:394-403.

9. Lausberg HF, Aicher D, Kissinger A, Langer F, Fries R, Schafers HJ Valve repair in aortic regurgitation without root dilatation-aortic valve repair. Thorac Cardiovasc Surg. 2006;54:15-20.

10. Carpentier A. Cardiac valve surgery-the "French correction." J Thorac Cardiovasc Surg. 1983;86:323-37.

11. Chauvaud S, Serraf A, Mihaileanu S, Soyer R, Blondeau P, Dubost C, et al. Ventricular septal defect associated with aortic valve incompetence: results of two surgical managements. Ann Thorac Surg. 1990; 49:875-80

12. Casselman FP, Gillinov AM, Akhrass R, Kasirajan V, Blackstone EH, Cosgrove DM. Intermediate-term durability of bicuspid aortic valve repair for prolapsing leaflet. Eur J Cardiothorac Surg. 1999;15:302-8.

13. Ross DN. Surgical reconstruction of the aortic valve. Lancet. 1963;1: 571-4.

14. Grinda JM, Latremouille C, Berrebi AJ, Zegdi R, Chauvaud S, Carpentier AF, et al. Aortic cusp extension valvuloplasty for rheumatic aortic valve disease: midterm results. Ann Thorac Surg. 2002;74:43843.
15. Al Halees Z, Gometza B, Duran CM. Aortic valve repair with bovine pericardium. Ann Thorac Surg. 1998;65:601-2.

16. Lausberg HF, Aicher D, Langer F, Schafers HJ. Aortic valve repair with autologous pericardial patch. Eur J Cardiothorac Surg. 2006;30: 244-9.

17. Alsoufi B, Karamlou T, Bradley T, Williams WG, Van Arsdell GS, Coles JG, et al. Short and midterm results of aortic valve cusp extension in the treatment of children with congenital aortic valve disease. Ann Thorac Surg. 2006;82:1292-9.

18. Al Halees Z, Al Shahid M, Al Sanei A, Sallehuddin A, Duran C. Up to 16 years follow-up of aortic valve reconstruction with pericardium: a stentless readily available cheap valve? Eur J Cardiothorac Surg. 2005;28:200-5.

19. Schafers HJ, Bierbach B, Aicher D. A new approach to the assessment of aortic cusp geometry. J Thorac Cardiovasc Surg. 2006;132:436-8.

20. Wilkenshoff UM, Kruck I, Gast D, Schroder R. Validity of continuous wave Doppler and colour Doppler in the assessment of aortic regurgitation. Eur Heart J. 1994;15:1227-34.

21. Kai H, Koyanagi S, Takeshita A. Aortic valve prolapse with aortic regurgitation assessed by Doppler color-flow echocardiography. Am Heart J. 1992;124:1297-304.

22. Cohen GI, Duffy CI, Klein AL, Miller DP, Cosgrove DM, Stewart WJ. Color Doppler and two-dimensional echocardiographic determination of the mechanism of aortic regurgitation with surgical correlation. $J$ Am Soc Echocardiogr. 1996;9:508-15.

23. Starr A, Menasché V, Dotter C. Surgical correction of aortic insufficiency associated with ventricular septal defect. Surg Gynecol Obstet. 1960;111:71-6.

24. Garamella JJ, Cruz AB Jr, Heupel WH, Dahl JC, Jensen NK, Berman R. Ventricular septal defect with aortic insufficiency. Successful surgical correction of both defects by the transaortic approach. Am J Cardiol. 1960;5:266-72.

25. Trusler GA, Williams WG, Smallhorn JF, Freedom RM. Late results after repair of aortic insufficiency associated with ventricular septal defect. J Thorac Cardiovasc Surg. 1992;103:276-81.

26. Spencer FC, Bahnson HT, Neill CA. The treatment of aortic regurgitation associated with a ventricular septal defect. J Thorac Cardiovasc Surg. 1962;43:222-33.

27. Beck A, Thubrikar MJ, Robicsek F. Stress analysis of the aortic valve with and without the sinuses of Valsalva. J Heart Valve Dis. 2001;10: $1-11$.

28. David TE, Armstrong S, Ivanov J, Webb GD. Aortic valve sparing operations: an update. Ann Thorac Surg. 1999;67:1840-2.

29. Pretre R, Kadner A, Dave H, Bettex D, Genoni M. Tricuspidisation of the aortic valve with creation of a crown-like annulus is able to restore a normal valve function in bicuspid aortic valves. Eur J Cardiothorac Surg. 2006;29:1001-6.

30. Tolan MJ, Daubeney PE, Slavik Z, Keeton BR, Salmon AP, Monro JL. Aortic valve repair of congenital stenosis with bovine pericardium. Ann Thorac Surg. 1997;63:465-9.

\section{Discussion}

Dr Christopher M. Feindel (Toronto, Ontario, Canada). Thank you very much, Dr Aicher. I have a couple of questions. Did you discover any relationship with what you saw at surgery, that is, any residual AR right at the time of surgery? Was there a relationship between those patients and the late failures and could you draw any conclusions from those observations?

Dr Aicher. We saw a few patients who had AR early postoperatively, and those patients showed increasing AR over time and were reoperated on later.

Dr Feindel. I noticed that approximately two thirds of your patients had aortic root surgery. I am assuming that was the primary reason for the surgery. Did those patients have a different failure mode down the road as compared 
with the patients in whom there was primarily a leaflet problem?

Dr Aicher. We had 196 patients with a root procedure in that study. Comparing the results of patients having a root procedure with those having no root procedure shows that the results are indeed better for those who had a root procedure, with a freedom from reoperation at 5 years of $97 \%$ compared with $90 \%$ without a root procedure. We had 1 reoperation owing to secondary root dilatation; all the other reoperations were due to cusp problems.

Dr Feindel. My final question relates to your use of the effective leaflet height and the little measuring instrument that I saw in the article. Did you find that this was very helpful or did you find, like many of us who are involved with valve-sparing procedures, that often it is really an eyeballing technique? In other words, should we all go out and buy this device?

Dr Aicher. The recognition of cusp prolapse is mainly dependent on surgical judgment and is thus subjective by definition. Prolapse of one or two cusps may be recognized by comparing the cusp free margins, but the recognition of prolapse of all cusps is much more difficult. That was the reason why, in the beginning when we started repairing AVs, trileaflet prolapse was the criterion to replace the valve. Since we measure the effective height, we have a more objective tool for cusp configuration. We are now able to better recognize and also treat a trileaflet prolapse. From my point of view, the effective height should not replace eyeballing but rather support it, especially in a symmetrical prolapse. Moreover, it should improve standardization of AV repair. Another advantage of effective height is that it can be measured intraoperatively as well as by echocardiography. In a retrospective echo analysis, we found an inverse correlation between the effective height and valve stability. Patients with an effective height of 7 to $10 \mathrm{~mm}$ show a stable result, whereas patients with an effective height lower than 7 mm show increasing AR. This observation emphasizes the importance of the effective height.

Dr Feindel. Thank you for a terrific paper. Even though the follow-up is a little bit soon, I think we are all going to look forward to seeing your long-term follow-up.

Dr Michael K. Banbury (Newark, Del). It is not unusual in patients who have tricuspid AVs to see some separation between the AV annulus and the aorta in the right coronary cusp. In fact, sometimes we even see some of the right ventricular muscle through that thin veneer. Did you note that in your patients and in the operative notes? If so, was that a risk factor for the 7 patients who had early recurrence of cusp prolapse?

Dr Aicher. I really did not know that problem, did not see it in the echocardiograms, and did not know that it is a risk factor for reoperation in our series.

Dr Gosta B. Pettersson (Cleveland, Ohio). I very much enjoyed your paper and the concept of effective height. I have a question regarding the bicuspid valves and your definition of normal cusp configuration in relation to the conjoint cusp.

The conjoint cusp of a bicuspid valve is composed of two components, two incompletely fused cusps with a raphe in most of the cases, and it is seldom that you have a prolapsing cusp, which you can repair to give it the configuration a normal cusp. You end up with some kind of compromise. My thought actually goes in the direction of the postrepair function of this valve with regard to doming of the valve and residual gradient and the relation between elimination of AR versus giving these patients some degree of stenosis and higher postrepair gradient. That is really what it relates to. 